\title{
NOTA SOBRE A CONSERVAÇÃO DE UM PÚCARO CERÂMICO DO SÍTIO LADEIRA DA BARROQUINHA,
}

\section{SALVADOR, BAHIA}

CARLOS ALBERTO SANTOS COSTA, UNIVERSIDADE FEDERAL DO RECÔNCAVO DA BAHIA, CACHOEIRA, BAHIA, BRASIL

Orcid: http://orcid.org/0000-0003-1204-322X

E-mail: carloscosta@ufrb.edu.br

CARLOS ALBERTO ETCHEVARNE, UNIVERSIDADE FEDERAL DA BAHIA, SALVADOR, BAHIA, BRASIL Orcid: http://orcid.org/0000-0003-2817-5788

E-mail: etchevarnebahia@gmail.com

FABIANA COMERLATO, UNIVERSIDADE FEDERAL DO RECÔNCAVO DA BAHIA, CACHOEIRA, BAHIA, BRASIL

Orcid: http://orcid.org/0000-0003-4675-1224

E-mail: fabianacomerlato@gmail.com

RITTA MARIA MORAIS CORREIA MOTA, UNIVERSIDADE FEDERAL DA BAHIA, SALVADOR, BAHIA, BRASIL

Orcid: http://orcid.org/0000-0002-8571-8673

E-mail: rittamaria_historia@yahoo.com.br

SILVANA SANTANA REIS, UNIVERSIDADE FEDERAL DO RECÔNCAVO DA BAHIA, CACHOEIRA, BAHIA, BRASIL

E-mail vanamorena1611@gmail.com

VIVIANE SILVA SANTOS, UNIVERSIDADE FEDERAL DO RECÔNCAVO DA BAHIA, CACHOEIRA, BAHIA, BRASIL

Orcid: http://orcid.org/0000-0001-7308-7571

E-amil: viviane.santos@ufrb.edu.br

RECEBIDO

DOI

http://doi.org/10.11606/issn.1980-4466.v16i31p358-370 


\section{NOTA SOBRE A CONSERVAÇÃO DE UM PÚCARO CERÂMICO DO SÍTIO LADEIRA DA BARROQUINHA, SALVADOR, BAHIA}

CARLOS ALBERTO SANTOS COSTA, CARLOS ALBERTO ETCHEVARNE, FABIANA COMERLATO, RITTA MARIA MORAIS CORREIA MOTA, SILVANA SANTANA REIS, VIVIANE SILVA SANTOS

\section{RESUMO}

Neste artigo abordamos um púcaro inteiro que foi localizado nas escavações arqueológicas da Ladeira da Barroquinha, no centro histórico de Salvador, Bahia. O púcaro é uma peça rara, uma espécie de caneca cerâmica personalizada, de paredes muito finas ( $3 \mathrm{~mm}$ ) e produção refinada, utilizada no Brasil pelas classes mais abastadas do período colonial. Demonstramos a inserção institucional de realização das atividades, os diferentes agentes que participaram desse processo e os contextos histórico e arqueológico, além da contextualização socioeconômica e das ações de conservação no recipiente.

PALAVRAS-CHAVE

Cerâmica, Artefatos arqueológicos, Conservação preventiva. 


\section{A NOTE ON THE ARCHAEOLOGICAL CONSERVATION OF A CERAMIC MUG (PÚCARO) FROM THE LADEIRA DA BARROQUINHA SITE, SALVADOR, BAHIA}

CARLOS ALBERTO SANTOS COSTA, CARLOS ALBERTO ETCHEVARNE, FABIANA COMERLATO, RITTA MARIA MORAIS CORREIA MOTA, SILVANA SANTANA REIS, VIVIANE SILVA SANTOS

\section{ABSTRACT}

In this article we approach a whole mug (púcaro) found in the archaeological excavations of Ladeira da Barroquinha, Historic Center of Salvador, Bahia. Púcaro refers to a rare piece, a kind of personalized ceramic mug, with very thin walls $(3 \mathrm{~mm})$ and refined production, used in Brazil by the wealthiest classes of the colonial period. Here, we show the institutional roles in carrying out the activities; the different agents that participated in this process; the historical, archaeological, and socioeconomic context; and the conservation initiatives on the container.

KEYWORDS

Ceramics, Archeological artifacts, Preventive conservation. 


\section{CONTEXTO INSTITUCIONAL}

Este artigo trata do trabalho de conservação realizado em um púcaro cerâmico, no âmbito do Laboratório de Documentação e Arqueologia (Lada) do Centro de Artes, Humanidades e Letras (CAHL) da Universidade Federal do Recôncavo da Bahia (UFRB). O artefato foi coletado nas escavações do sítio arqueológico Ladeira da Barroquinha, no Centro Histórico de Salvador, desenvolvida pelo Laboratório de Arqueologia, da Faculdade de Filosofia e Ciências Humanas (FFCH), da Universidade Federal da Bahia (UFBA).

O estudo do púcaro teve a participação de Silvana Santana Reis, com a produção de trabalho de conclusão de curso de Museologia, realizado sob a orientação de Viviane da Silva Santos (professora de conservação do curso de Museologia), com supervisão técnica de Ritta Maria Morais Correa Mota (técnica em restauração do CAHL/UFRB) e acompanhamento técnico, arqueológico e institucional de Fabiana Comerlato e Carlos Alberto Santos Costa (professores do curso de Museologia e coordenadores do Laboratório de Documentação e Arqueologia da UFRB). As escavações arqueológicas foram coordenadas por Carlos Alberto Etchevarne (arqueólogo, professor titular da Universidade Federal da Bahia); e o campo de pesquisas foi liderado por Márcia Cristina Labanca, Mirta Kelen Barbosa Bezerra e Alvandyr Dantas Bezerra, pesquisadores na área de Arqueologia. O financiamento das atividades de campo e laboratório na UFBA coube à Ekosocial Engenharia Ltda. 
O Laboratório de Documentação e Arqueologia (Lada) foi criado em 2007 com o objetivo de proporcionar aos estudantes da UFRB, em especial àqueles do curso de Museologia, a formação prática e acadêmica em atividades de ensino, pesquisa e extensão no campo interdisciplinar entre a Museologia e a Arqueologia. Nesse espaço são realizadas ações institucionais e interinstitucionais (mediante convênio de cooperação técnica/ acadêmica) de pesquisa, ensino de graduação e pós-graduação, iniciação científica, iniciação à extensão, iniciação ao ensino, promoção de eventos, estágios curriculares e extracurriculares, monitorias e publicação para diversos públicos e com diferentes alcances, em que discentes, técnicos e docentes interagem na produção e promoção de novos conhecimentos. Este trabalho é um exemplo do fluxo ocorrido no Lada.

Uma vez retirado do sítio, a conservação integra as atividades de tratamento dos materiais arqueológicos de toda natureza (orgânica ou inorgânica), com o objetivo de prolongar a sua vida útil, sem alterar ou interferir na leitura física e informacional do objeto. Há anos o laboratório desenvolve atividades de conservação em artefatos arqueológicos, por meio de uma atuação interdisciplinar que visa, a partir do diálogo entre discentes, técnicos e docentes, promover maior articulação dos conhecimentos teóricos e práticos. São ações comprometidas com a ética e o rigor científico que seguem metodologias de atuação, atendendo a critérios específicos do trabalho desenvolvido.

Como norte do trabalho em equipe e orientação dos estudantes que atuam no Lada, estão sempre evidenciados os conceitos de preservação, conservação e restauração. Preservação é um conjunto de medidas e estratégias de ordem administrativa, política e operacional que contribui direta ou indiretamente para a integridade dos materiais; conservação refere-se a um conjunto de ações estabilizadoras que visam desacelerar o processo de degradação do patrimônio cultural, por meio de controle ambiental e tratamentos específicos - como higienização, reparos e acondicionamento; e, por fim, restauração é o conjunto de medidas que objetiva estabilizar ou reverter danos físicos ou químicos sofridos pelo bem ao longo do tempo, evitando interferências que afetem o valor estético e documental do patrimônio. Mais do que operar com conceitos, esse processo de evidenciação de definições serve para explicitar os limites das ações desenvolvidas no laboratório. 


\section{CONTEXTO HISTÓRICO E ARQUEOLÓGICO}

O trabalho de escavação na área da Barroquinha, denominado "Projeto Ladeira da Barroquinha", foi aprovado pelo Instituto do Patrimônio Histórico e Artístico Nacional (Iphan) e realizado entre setembro de 2017 e agosto de 2018. A área da Barroquinha, no bairro do Pelourinho, Centro Histórico de Salvador, corresponde a uma ocupação urbana definitiva ocorrida na terceira década do século XVIII, com a fundação da Igreja da Barroquinha. Esse setor estava num dos extremos da área mais antiga de ocupação da cidade, na porção Sul, haja vista que ali estava localizada a porta de São Bento, que delimitava as muralhas defensivas da Salvador colonial, entre os séculos XVI a XVIII. Nesse contexto, o templo religioso estava situado à margem de edifícios importantes da região, como o solar Berquó e a Igreja de São Bento, além da própria malha urbana.

A Ladeira da Barroquinha, localizada na periferia dessa área, começa

FIGURA 1a

"Pranta da Çidade D. Salvador/na Bahia de Todos os Santos" que ilustra o códice "Livro que dá Rezão do Estado do Brasil", de autoria de João Teixeira Albernaz I. em 1605 [ca. 1626] (SIMAS FILHO, 1998, p. 59) a ser ocupada somente a partir da edificação de uma capela na segunda década do século XVIII. Como era comum no período colonial, o edifício religioso foi o elemento guia da expansão urbana de Salvador, que, neste caso, se consolidaria definitivamente já no século XIX. Esse setor da cidade era pouco privilegiado em termos espaciais, possivelmente em função da sua topografia abrupta e por se localizar na área limite do perímetro urbano. Por isso, sua ocupação merece, por várias razões, especial atenção.

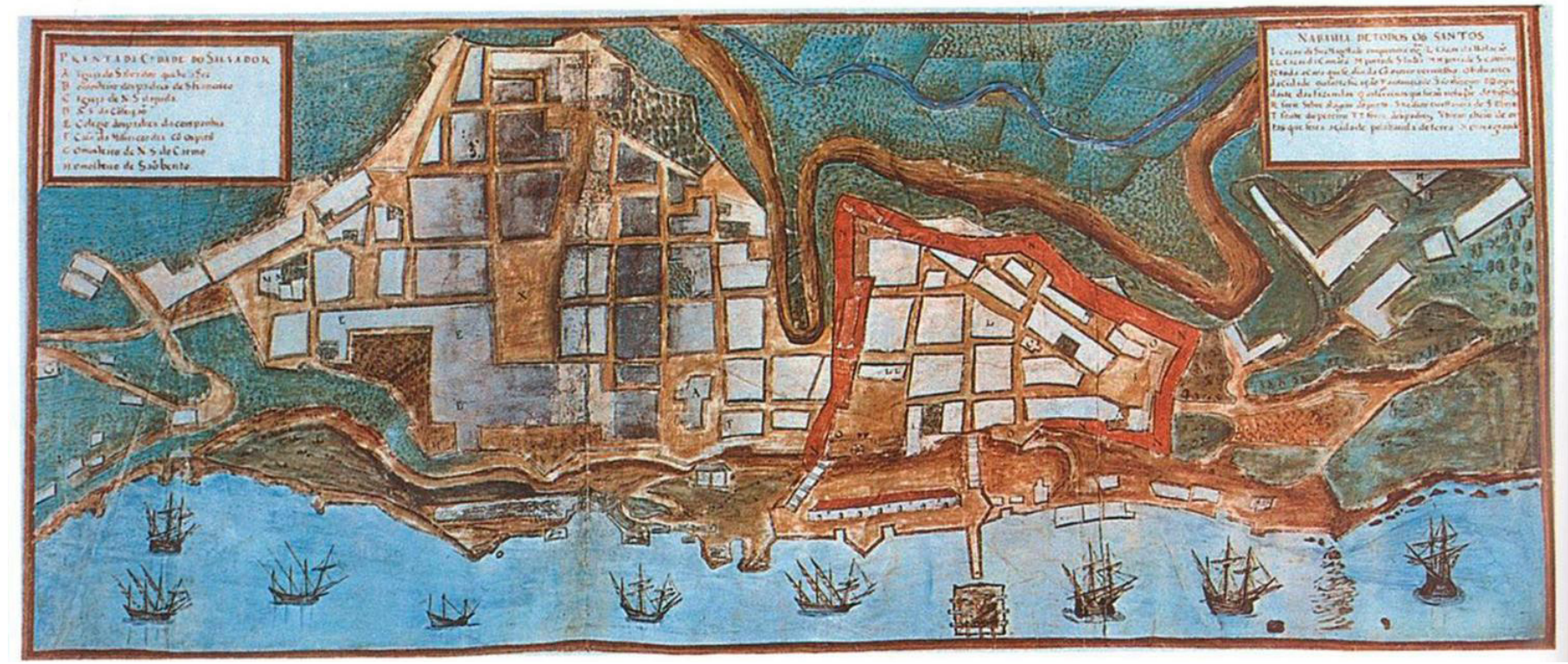


FIGURA 1b

Acima, imagem aérea atual do centro histórico da cidade de Salvador, no

mesmo ângulo da imagem de Albernaz, na qual se destaca pelo tracejado azul a área onde está localizada a Igreja da Barroquinha (Google Earth, 2020)

Abaixo, à esquerda ampliação da

seleção da imagem anterior, com a igreja da Barroquinha centralizada. Abaixo no centro, área de escavação ao lado da igreja, de onde saiu o púcaro Fotografia: Márcia Labanca 2018. Abaixo, a direita, sondagem de onde saiu o púcaro com escavação finalizada Fotografia: Márcia Labanca, 2018.

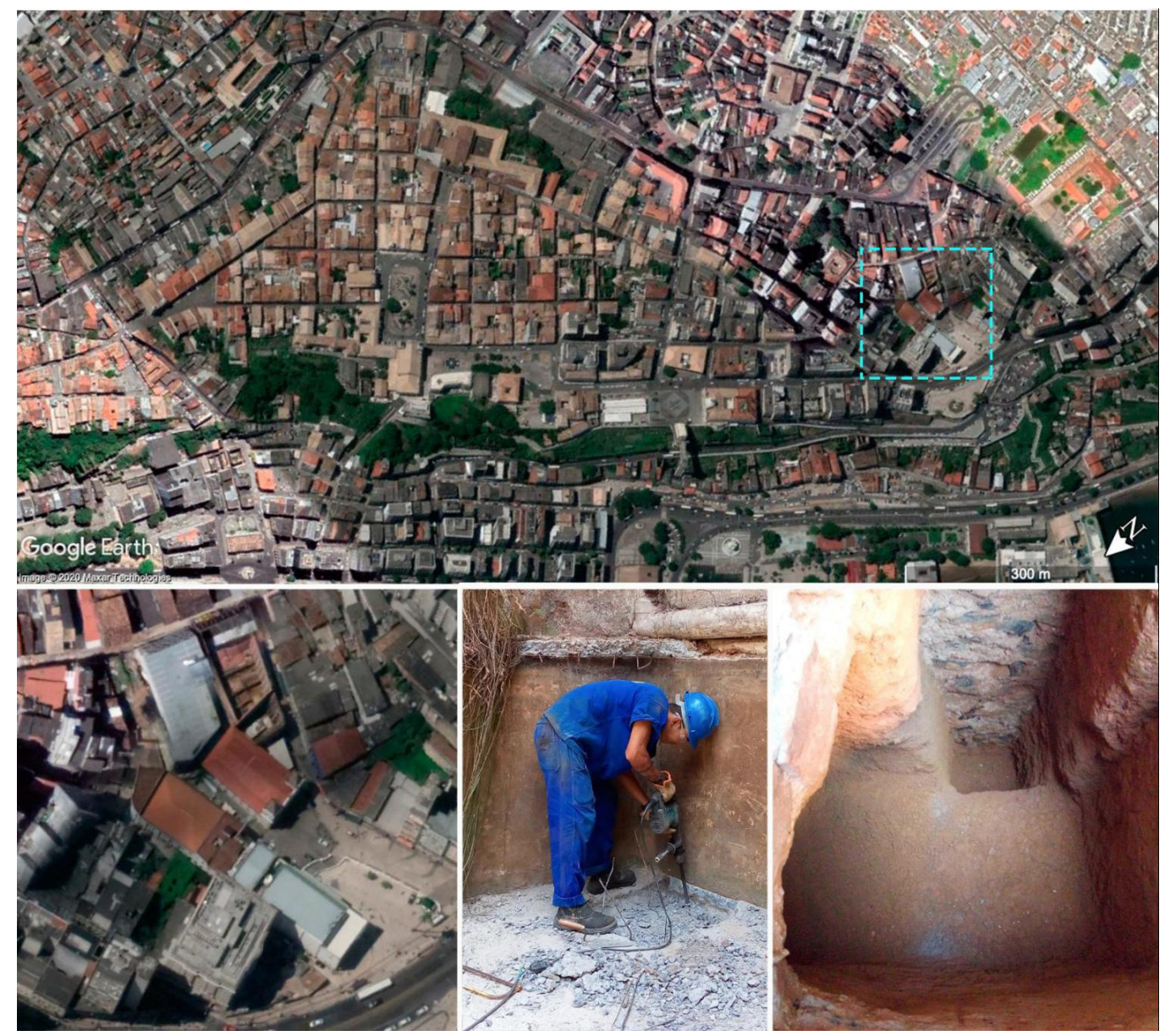

Nesse contexto, a Igreja da Barroquinha tem uma inserção espacial pouco comum, uma vez que está localizada numa meia encosta, encravada no fundo de uma depressão da colina e abaixo das ruas principais. Essa posição permite que a visualização do edifício na malha urbana se dê de cima para baixo, sem se impor, com a sua estrutura, sobre as construções de seu entorno (como é comum nos edifícios das igrejas). Além disso, a igreja está fora do padrão de outros templos encontrados em Salvador e até mesmo nas ocupações coloniais portuguesas no Brasil. Este fator denota o pouco prestígio desse templo na ordem eclesiástica da cidade.

As escavações arqueológicas realizadas no entorno da igreja e em casarões de 1820 a 1830 contíguos ao edifício religioso permitiram identificar alguns pisos, que indicam a existência de residências simples antes dessas ocupações. Apesar dessa antecedência mais singela, foram os referidos 
casarões e a igreja que criaram a diretriz de como se expandiria esse setor da cidade, à medida que definem os alinhamentos e delimitam as ruas, impondo uma nova ordem e condicionando o crescimento urbano.

Para essa expansão e para a ocupação da ribanceira em que se localizavam as residências e a igreja, foi necessário o preenchimento dos declives com material residual secundário. Trata-se de soluções que podem ser classificadas como práticas e expeditas, em função da necessidade de aterrar as depressões e superar a declividade da ladeira e os desníveis naturais do terreno. O lixo da cidade, de tipo doméstico, junto ao descarte dos abatedouros nas margens do Rio das Tripas, localizados na base da Ladeira da Barroquinha, foram utilizados como material de construção e para nivelar as ruas. Foi nesse aterro que se localizou o púcaro.

\section{SOBRE O PÚCARO E A SUA CONSERVAÇÃO}

Coletado intacto, em janeiro de 2018, o púcaro estava inserido num solo arenoso-ferroso, compactado e úmido. Esse artefato foi coletado a 1,2 metro de profundidade, numa sondagem realizada no fundo do antigo Hotel Castro Alves. Durante a coleta foram adotados, como medida de conservação e preservação informacional, o acondicionamento do objeto em sacos acolchoados e vedados, assim como o registro de identificação no contexto arqueológico por meio de etiquetas. Para a guarda definitiva e o transporte - para a FFCH ou para o Lada, onde teve o tratamento de conservação - o vasilhame foi acomodado em recipiente plástico vedado, com adequação de acondicionamento própria para as características do objeto.

No Lada, foram adotadas como metodologia de preservação informacional e de conservação-restauração:

a) a pesquisa sobre o objeto;

b) preenchimento da ficha de identificação, documento imprescindível, já que se trata de um registro técnico especifico para os trabalhos de conservação-restauração, e auxilia na manutenção das informações rotineiras de conservação;

c) documentação fotográfica, realizada com luz natural e luz ultravioleta, produzindo macrofotografia e microfotografias de detalhes como abrasões, fissuras, fracionamentos, identificação de cores, possíveis 
O púcaro é um objeto de origem portuguesa, mas seu nome é espanhol, de significado incerto. Suas características assemelham-se às de um pequeno jarro, com forma fechada, cilíndrica e uma alça em forma de asa. Era utilizado como louça refinada de mesa para consumo exclusivo de água. Trata-se de um artigo de luxo utilizado, pelo menos em certos períodos, pelas classes nobres e até pela realeza. De fato, entre o final do século XVI

FIGURA 3

Pintura "As meninas", óleo sobre tela, de Diego Velázquez, 1656

Notar a ampliação

à direita, do detalhe tracejado em azu

na imagem da esquerda. Trata-se da representação de um púcaro no contexto de uso da nobreza espanhola. Fonte: acervo do Museu do Prado, Madrid. e o século XVII, ou seja, durante o domínio dos Habsburgos na Península Ibérica, as famílias abastadas impuseram o uso dos púcaros, fabricados especialmente na região do Alentejo.

Nesse sentido, é bastante ilustrativo o quadro de Diego Velazquez, intitulado As meninas, em que o pintor retrata a filha do rei Felipe IV, a infanta Margarita de Áustria, em primeiro plano, com outras crianças da nobreza espanhola. Ela está sendo servida por outra criança, em bandeja de prata, sobre a qual observa-se unicamente um púcaro vermelho. Algumas décadas antes, Felipe II da Espanha envia a suas filhas púcaros de Portugal, tecendo comentários elogiosos sobre eles.
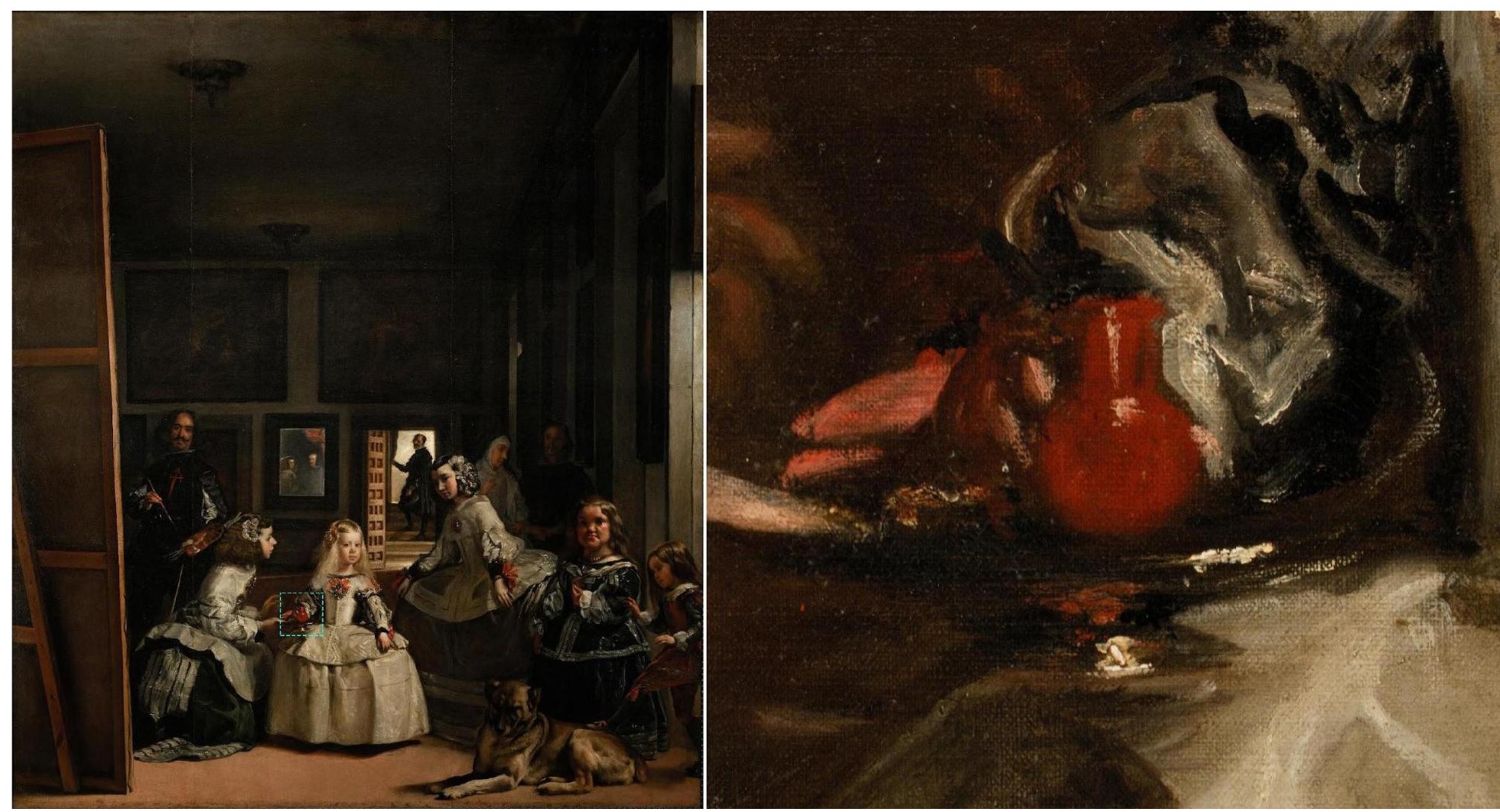
A corte luso-hispânica impôs o modismo do seu uso que, como todo modelo de comportamento de nobreza, foi imitado, dentro das possibilidades, pelos outros estamentos sociais. Assim, à medida que se torna popular, o uso do púcaro vai se tornando menos prestigioso, até cair, ao longo do tempo, em desuso.

$\mathrm{Na}$ colônia brasileira, outros exemplos de púcaros confeccionados em Portugal foram encontrados durante as escavações realizadas na Praça da Sé de Salvador, mas nenhum deles estava no total grau de integridade como o da Barroquinha. De todo modo, a presença deles é um excelente indicador de que o púcaro atuava como elemento diacrítico de classes opulentas.

O púcaro estudado no Lada tem a forma típica de jarro, feito em suporte cerâmico de cor avermelhada, coberto por um engobe vermelho, brunhido. Nas paredes externas aparecem pequenas manchas escuras. Mede $10,9 \mathrm{~cm}$ de altura, $12,4 \mathrm{~cm}$ de largura, $10,6 \mathrm{~cm}$ de diâmetro e $3 \mathrm{~mm}$ de espessura da pasta cerâmica. Em termos de forma geral, o corpo da peça é robusto, dividido em duas grandes seções: da base até a metade da peça a forma é redonda e levemente achatada; da metade da peça até a borda forma-se um cilindro largo, conformando um gargalo. A parte externa da seção cilíndrica tem uma sequência de linhas paralelas diagonais com distância e entre si e largura das linhas de o,1 $\mathrm{mm}$ ou pouco inferior. Possui marcas de manipulação feitas na hora da fabricação, leve desgaste em algumas áreas, sinais de pequenas perdas do suporte ou de excesso de cerâmica, causando alto relevo, talvez características naturais do processo de fabricação manual. A alça é estreita e bem delicada, apresentando desnível na junção da alça inferior.

Foi possível identificar, por meio dos processos de documentação fotográfica com luz natural e luz ultravioleta, dos exames organolépticos e dos exames com lupa em mesa de luz, sujidades, abrasões, perda do suporte, fungos, pequenas vegetações, marcas de fabricação e alterações da coloração -avermelhadas, acinzentadas e em cor preta. Na parte interna, foram identificadas marcas de escorrimento do engobo líquido e fungos, adquiridos pós deposição. Por meio do exame de percussão percebeu-se diferença sonora em partes da alça e do bojo.

Com a microscopia, com zoom 200x, foi possível confirmar indícios analisados nos exames a olho nu, a exemplo da alteração de cor proveniente de concentração de material na fabricação, eflorescência, processo químico 
resultado da queima da argila, microrraízes, riscos de fabricação, entre outros indícios detalhados nas imagens.

Através do exame de Raio-X foi possível identificar que a alça possui uma área muito fragilizada em decorrência de bolhas formadas no interior da pasta cerâmica durante o processo de fabricação. Essa informação é de extrema importância, pois define a forma de manipulação e acondicionamento do vaso. O Raio-X também identificou as angulações do púcaro e áreas de maior sensibilidade.

Devido às marcas de escorrimento na parte interna do púcaro, percebeu-se a necessidade de exames microbiológicos em diversos meios de cultura, visando identificar fungos e bactérias, além de desenvolver estudo sobre o possível líquido. Infelizmente, por questões financeiras, limitamo-nos às culturas em meios PCA e Cromocult, que identificaram contaminação higiênica sanitária, com proliferação de mesofílicos, bolor e levedura.

Com o resultado desses exames e discussões em grupos, entendeu-se que os procedimentos de conservação no púcaro deveriam ser feitos apenas na parte externa. Assim, foi realizada a proposta de tratamento em higienização mecânica com escova de cerda macia, remoção de sedimentos e concreções com palito de madeira e espátula de metal. A limpeza química foi realizada com água deionizada em swab levemente úmido.
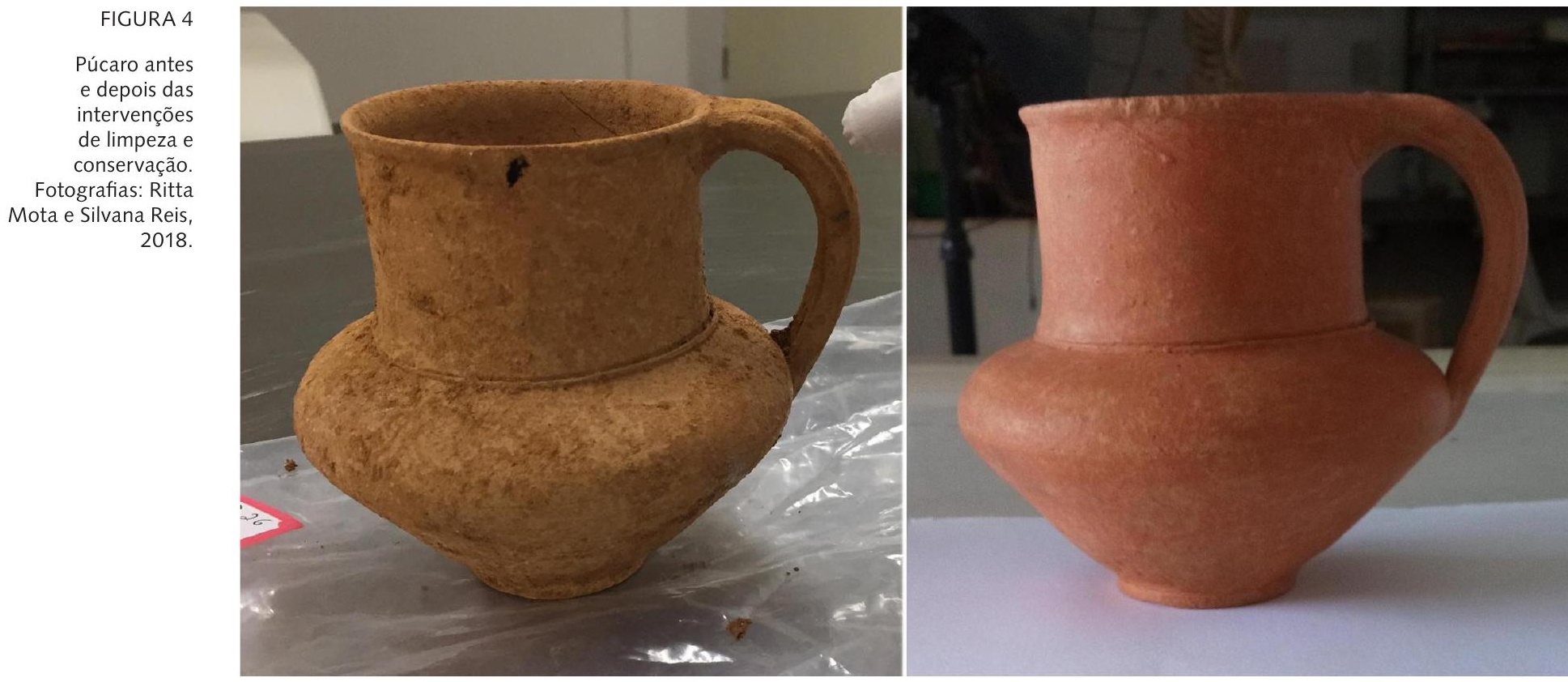


\section{CONSIDERAÇÕES FINAIS}

O registro dessa intervenção decorre da importância desse recipiente enquanto elemento evocativo dos diversos trânsitos culturais entre Brasil e Europa. E, além disso, também é relevante devido ao estado de conservação e à singularidade do objeto.

Os trabalhos realizados e os resultados obtidos só foram possíveis em razão da qualidade dos dados coletados nas escavações arqueológicas, da adoção de procedimentos de conservação já durante a coleta e acondicionamento inicial, e da conjunção de esforços de diferentes equipes na elaboração das análises e preparação do objeto para a salvaguarda institucional.

\section{REFERÊNCIAS}

ETCHEVARNE, Carlos Alberto; BEZERRA, Alvandyr Dantas; LABANCA, Márcia Cristina Labanca; Bezerra, Mirta Kelen Barbosa. Ladeira da Barroquinha, Salvador-BA: avaliação do potencial arqueológico (relatório de pesquisa). Salvador: FFCH/UFBA, 2019.

ETCHEVARNE, Carlos Alberto Etchevarne; OLIVEIRA, Júlio César Mello de. Curso de restauração da cerâmica histórica, artística e arqueológica. Roma: Instituto Ítalo-Latino Americano, 2003.

REIS, Silvana Santana. Conservação preventiva de um púcaro do século XVII, Ladeira da Barroquinha, Salvador - Bahia. 2019. Trabalho de Conclusão de Curso (Bacharelado em Museologia) - Centro de Artes, Humanidades e Letras Universidade Federal do Recôncavo da Bahia, Cachoeira, 2019.

SIMAS FILHO, Américo. Evolução física de Salvador (1549-180o). Salvador: Fundação Gregório de Mattos, 1998.

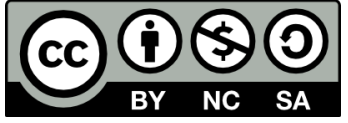

